\title{
Information Signal Quality and Risky Project Evaluation in Organizations (Environment, Adoptability and Choice-Hierarchies and Polyarchies)
}

\author{
Akin Seber ${ }^{1}$ \\ ${ }^{1}$ Department of Financial Economics and Faculty of Commercial Sciences, Yeditepe University, Istanbul, Turkey \\ Correspondence: Akin Seber, Department of Financial Economics and Faculty of Commercial Sciences, Yeditepe \\ University, Inonu Mah., Kayisdagi Cad., 26 Agustos Yerlesimi, Atasehir 34755, Istanbul, Turkey. E-mail: \\ aseber@yeditepe.edu.tr
}

Received: June 5, 2014

Accepted: June 19, 2014

Online Published: August 25, 2014

doi:10.5539/ijef.v6n9p228

URL: http://dx.doi.org/10.5539/ijef.v6n9p228

\begin{abstract}
In this paper, risky project evaluation in organizations is modelled in a linear information signal framework, which enables the following multidimensional analysis: "Ability"-Agents may have different abilities in processing information for risky project evaluation; "Endogenity"-It is possible to choose the organization type internally, or the organization type may be determined externally by the environment, in which case it is necessary for the evaluation criteria to adopt to the environment; "Sensitivity"-Risky and risk-free alternatives may not necessarily be equal with positive risk sensitivity and positive price of risk; "Project Quality"-The project quality may always be a certain type, for example, fixed (below or above average all the time) or it may be variable, which may affect the evaluation criteria; "Communication"-Communication between the agents may be in an information quality improving or detoriorating manner; "Coordination"-There may be an existance problem for the organization (it may exist due to an external setup, or from internal dynamics), and there may be a need for coordination between the agents in case it exists with internal dynamics. Risky project evaluation in organizations with a specific information signal quality has not been analyzed in the literature before and is a contribution of this paper. As a result of the analysis, most of the multidimensional variables mentioned in organizational decision making are original and specific to our paper. The results of the analysis have policy implications in all types of organizational settings of collective decision-making environments like family, firm, government, education, military, politics, and economic systems.
\end{abstract}

Keywords: risky project evaluation, hierarchy, polyarchy, organizational design, information signal quality, ability of agents, sensitivity to risk, project quality, communication, coordination

\section{Introduction}

Since human judgments are fallible, evaluation and acceptance or rejection of projects are subject to errors. Organizations with multiple evaluators can circumvent the limitations of a single individual's capacity in information gathering and processing and reduce errors. As mentioned in a latest research paper in this area, Koh (2005): "Over the past three decades, various aspects of collective decision-making in various contexts has been studied in the literature, which includes the following: Klevorick and Rotschild (1979), Nitzan and Paroush (1980, 1982, 1984, 1985), Klevorick et al. (1984); Sah and Stiglitz (1985, 1986, 1988), Gradstein et al. (1990), Sah (1990, 1991), Stiglitz (2002), Koh (1992a, b, 1993, 1994a, b), Pete et al. (1993), Austen-Smith and Banks (1996), Berg and Paroush (1998), Ben-Yashar and Nitzan (1997, 1998, 2001) and Ben-Yashar and Paroush (2001). Furthermore, the strategic aspects of collective decision-making in the committee setting have been examined by Feddersen and Pesedorfer (1998), Dekel and Piccione (2000), Li et al. (2001), Persico (2004), and others. Specifically, in a hierarchy and polyarchy setting, which has attracted attention in the literature, the following works are observed of Sah and Stiglitz (1985, 1986, 1988), Sah (1991), Koh (1992a, 1992b, 1994), Ben-Yashar and Nitzan (2001).”

In a series of seminal papers, Sah and Stiglitz $(1985,1986,1988)$ examine the decision making procedure in hierarchies and polyarchies. However, they have not defined a specific information signal in their analysis, and therefore, the cut-off point for deciding on acceptance and rejection of the risky project was not specified in their 
models. In an information setting of unobservable actions and principle-agent, Lambert (1986) introduces a specific information signal in his paper. Our analysis is similar to his, but we don't analyze the case for unobservable actions in this paper and refer to it in Seber and $\mathrm{Wu}(2000)$. On the other hand, Koh also analyzed sequential project analysis in a series of papers in an incomplete information setting (an example of which is given in Koh, 1992b). Our model is different because we have a different information signal, and we analyze the simultaneous evaluation case. Simultaneous and sequential analysis may be preferred according to the comparison of time costs and evaluation costs by the second agent if the project reaches him.

Among the other works done in this area are Ben-Yashar and Nitzan's several papers, an example of which is Ben-Yashar and Nitzan (1998). In this paper, they conclude that: "Comparison of organizations solely on the basis of the decision criteria (which they refer to as organizational quality), can be misleading. Generally, the organization's structure and size together with its decision criteria, determine its performance". In their model, individual decision-making skills are endogenously determined via the determination of organizational quality. On the contrary, in our model, we concentrate on a specific linear information signal, and the individual decision-making skills are exogenously determined based on the quality of the information signal. This enables a more precise determination of the decision-criteria as a function of project quality. Furthermore, we have a multidimensional analysis of project evaluation as stated below by limiting the organization size to 2 agents.

Visser is another researcher in this area, and an example of his work is given in Visser (2000). In this paper, he states that: "The effect of organizational communication structure on performance is examined using a project selection framework, in which heterogeneous, rational agents can accept or reject projects. A hierarchy performs better than polyarchy in tough environments, whereas the reverse holds true in friendly environments". The simpler framework we set up in this paper, also allows for analyzing the communication between agents among other dimensions of analysis, with similar results found in his paper.

The references given for this paper are not comprehensive with various researchers approaching the same problem from different perspectives. However, it suffices for our purposes since most of the multidimensional variables we analyze in the paper are original and are specific to our paper. Thus, the references given set the stage for our specific model.

The special characteristics of our model can be summarized as follows: By introducing a specific linear information signal, it is possible to analyze risky project evaluation in organizations in a multidimensional setting. These multidimensional variables have either not been analyzed before, or are not presented in such a simple framework as it is in our paper. Furthermore, this multidimensional analysis allows for simple intuitive prescriptions for policy implementations. The different dimensions of risky project evaluation in organizations we analyze in our paper can be summarized as:

a) Ability-Different abilities of agents are represented by the quality of a specific linear information signal.

b) Endogenity -The condition of whether the organization type is given as a "choice" variable-endogenous, or "adaptation" variable-exogenous, is important in determining the appropriate evaluation criteria and is analyzed in the paper.

c) Sensitivity-The risky and risk-free projects may be treated as equal alternatives only to the extent that riskignorant behavior prevails. In case the principle's risk sensitivity is greater than zero, and there is a price to risk as given by the Sharp Ratio (SR) (as analyzed in our recent paper Seber, 2014), the project quality will detoriorate and the organization choice will be different.

d) Project Quality-Different environments are analyzed about project quality, whether it is fixed-(below-above average at all times) or variable, which requires adoptation.

e) Communication-It is possible to improve information signal quality with prositive communication between the agents, but a negative communication would detoriorate information signal quality, both with their effects on performance of organizations.

f) Coordination-To the extent that the organizations exists with internal forces rather than external setup, there may be a need for coordination between the agents to keep the organization together.

\section{Model}

In the model it is assumed that there are two kinds of projects to be evaluated: a safe project and a risky project. The return from the safe project is a certain value of $x_{o}$. The return from the risky project is either high $x_{H}$ (if the project is good) or low $\mathrm{x}_{\mathrm{L}}$ (if the project is bad). The outcomes of these projects are ordered as $\mathrm{x}_{\mathrm{H}}>\mathrm{x}_{\mathrm{O}}>$ $\mathrm{x}_{\mathrm{L}}$. The performance of the two types of organizations (hierarchy and polyarchy) in the evaluation of safe and 
risky projects is studied and a comparison is made. These two organization types are shown in Figure 1.

The specific linear information signal defined in the paper plays a key role in the analysis. Without the information signal, the common prior (or optimism) that the risky project is a good one is $\pi$, which provides ex-ante information about the composition of the initial portfolio. The agents obtain signal $r_{i}$ after expanding effort. The agents accept the risky project if signal $r_{i}>\underline{r_{i}}$ where the reservation levels $r_{i}$ are given to the agents by the principle.

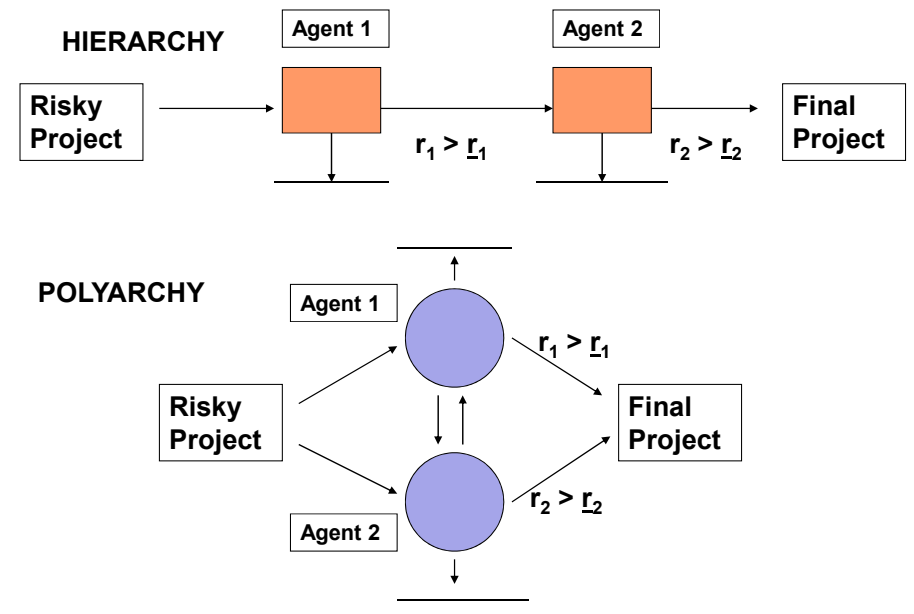

Figure 1. Evaluation of risky projects in organizations

The conditional probability of acceptance of a good project by agent $i$ is defined as $p_{i}^{d}$ and the conditional probability of acceptance of a bad project by agent $\mathrm{i}$ is defined as $\mathrm{q}_{\mathrm{i}}^{\mathrm{d}}$ where $d=H, P$. Therefore, the probabilities of different outcomes in hierarchy and polyarchy $\mathrm{f}_{\mathrm{k}}^{\mathrm{d}}$, for $k=1$, 2of the agents, are:

$$
\begin{gathered}
f_{H}^{H}=\pi\left(p_{1}^{H} p_{2}^{H}\right) \\
f_{L}^{H}=(1-\pi)\left(q_{1}^{H} q_{2}^{H}\right) \\
f_{o}^{H}=1-f_{H}^{H}-f_{L}^{H} \\
f_{H}^{P}=\pi\left(p_{1}^{P}+p_{2}^{P}-p_{1}^{P} p_{2}^{P}\right) \\
f_{L}^{P}=(1-\pi)\left(q_{1}^{P}+q_{2}^{P}-q_{1}^{P} q_{2}^{P}\right) \\
f_{o}^{P}=1-f_{H}^{P}-f_{L}^{P}
\end{gathered}
$$

The expected profit function of the principal can now be defined in hierarchy and polyarchy, where $s$ is the wage given to each agent determined in the competitive market.

$$
\begin{gathered}
Y^{d}=f_{o}^{d} x_{o}+f_{H}^{d} x_{H}+f_{L}^{d} x_{d}-2 s \\
=\left(f_{o}^{d}+f_{H}^{d}+f_{L}^{d}\right) x_{o}+f_{H}^{d}\left(x_{H}-x_{o}\right)+f_{L}^{d}\left(x_{o}-x_{L}\right)-2 s \\
=x_{o}+f_{H}^{d} y_{H}-f_{L}^{d} y_{L}-2 s
\end{gathered}
$$

where $y_{H}=x_{H}-x_{o}>0$ and $y_{L}=x_{o}-x_{L}>0$. On the other hand, the quality of the risky project $\alpha$ is defined as given below. We can also define the objective function $Z^{d}$ in terms of $\alpha$ :

$$
\begin{aligned}
\alpha & =\frac{\pi y_{H}}{(1-\pi) y_{L}} \in[0,1] \\
\frac{\alpha_{F}}{\alpha} & =\frac{(\pi-q)(1-\pi)}{(1-\pi+q) \pi}<1
\end{aligned}
$$

Equation (3b) above tells us that, if we don't treat the safe project and the risky project as equals, that is the principle is not risk-ignorant, then the quality of the risky project as represented by $\alpha$ would decrease. As given in our recent paper Seber (2014), the risk-adjusted probability measure is given by $\pi_{\mathrm{F}}=\pi-\mathrm{q}$, and $\mathrm{q}=$ $\mathrm{kSR} \sqrt{\pi(1-\pi)}$, where $\mathrm{k}$ is the risk-sensitivity of the agent (risk-normal, risk-sensitive, risk-insensitive, if 
$\mathrm{k}=1,>1,<1$, respectively); and SR is the Sharp Ratio determined from the equity market for determining the price of risk given by the equation $\mathrm{SR}=\left(\mu_{\mathrm{M}}-\mathrm{r}_{\mathrm{F}}\right) / \sigma_{\mathrm{M}}$ of the Capital Market Line-CML of the Capital Asset Pricing Model-CAPM. If we use the new definition of $\pi_{F}$ rather than $\pi$, we obtain equation (3b).

In order to represent the information signal, we assume a continuum of risky projects, each characterized by the information signal $r_{i}$ the project can generate. It is assumed the signal $r_{i}$ about the project that agent $\mathrm{i}$ can obtain is uniformly distributed: $h\left(r_{i}\right)=1$. The common prior for the project to be a good one is $\pi=\operatorname{Pr}\left(\mathrm{x}_{\mathrm{H}}\right)$. The posterior density of the risky project being good or bad after receiving the information signal $r_{i}$ is assumed to be linear for $r_{i} \in(0,1)$. After some manipulations, we obtain the following equations $(4 a-b)$ and Figure $2 a-b$, where the variable $b \in[0,2]$ stands for the slope of the linear information signal. Here, a higher slope would represent a "more precise signal-higher ability agent":

$$
\begin{aligned}
& g\left(r_{i} / \text { good }\right)=g\left(r_{i} / x_{H}\right)=b r+\left(1-\frac{b}{2}\right) \\
& g\left(r_{i} / \text { bad }\right)=g\left(r_{i} / x_{L}\right)=-b r+\left(1+\frac{b}{2}\right)
\end{aligned}
$$

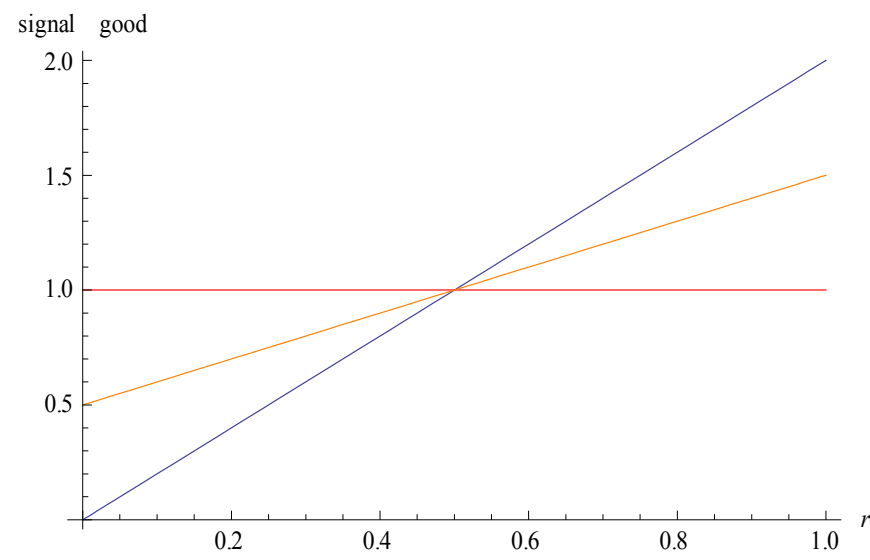

Figure 2a. The information signal conditional on the risky project being good, as given in equation (4a) for values of the slope variable $b=0,1,2$ respectively

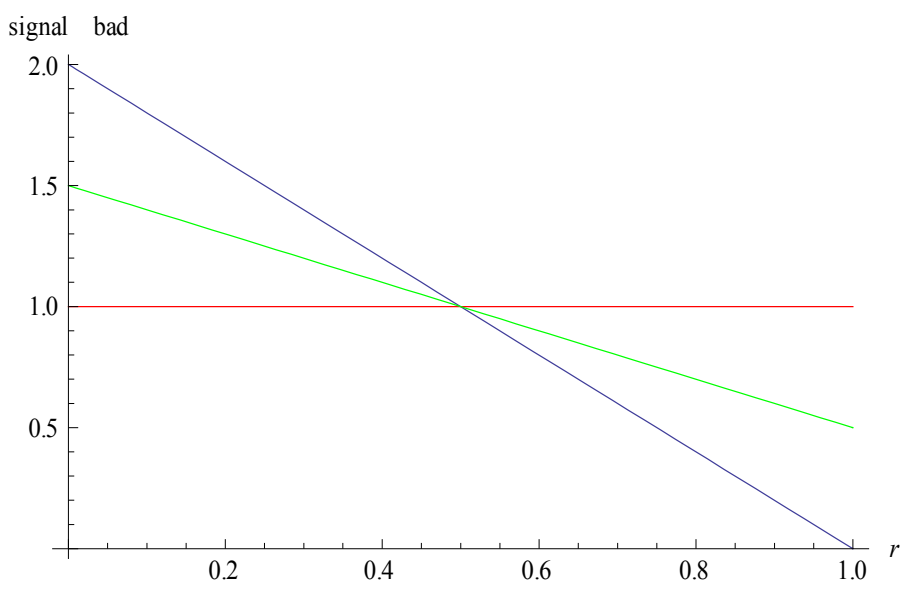

Figure $2 \mathrm{~b}$. The information signal conditional on the risky project being bad, as given in equation (4b) for values of the slope variable $b=0,1,2$, respectively

From the definitions, it is possible to estimate the mean and standard deviation of the information signals and the results are given in equations (5a-c) below. We can estimate that when $b=2,1,0$, the mean and standard deviation values are $\mu_{H}=2 / 3,7 / 12,1 / 2 ; \mu_{L}=1 / 3,5 / 12,1 / 2 ; \sigma_{H}=\sigma_{L}=\sigma=0.236,0.276,0.289$, respectively. These figures indicate that a better information signal-higher ability of agents, represented by a higher $b$, gives a more precise value in both variables of the mean and standard deviation. 


$$
\begin{gathered}
\mu_{H}=\int_{0}^{l} r g\left(r_{i} \mid x_{H}\right) d r=\frac{6+b}{12} \\
\mu_{L}=\int_{0}^{1} r g\left(r_{i} \mid x_{L}\right) d r=\frac{6-b}{12} \\
\sigma=\sigma_{H}=\sigma_{L}=\left[\int_{0}^{1}\left(r-\mu_{H}\right)^{2} g\left(r_{i} \mid x_{H}\right) d r\right]^{\frac{1}{2}}=\left[\int_{0}^{1}\left(r-\mu_{L}\right)^{2} g\left(r_{i} \mid x_{L}\right) d r\right]^{\frac{1}{2}}=\frac{\sqrt{12-b^{2}}}{12}
\end{gathered}
$$

In order to find optimum cut-off point selection of each organization type as a function of the project quality, we need to calculate the conditional probabilities $\mathrm{p}_{\mathrm{i}}^{\mathrm{d}}$ and $\mathrm{q}_{\mathrm{i}}^{\mathrm{d}}$ of accepting good or bad projects, given information signal $r_{i}^{d}$ as follows:

$$
\begin{aligned}
& p_{i}^{d}=P\left(r_{i}>\underline{r_{i}^{d}} \mid x_{H}\right)=\int_{\underline{r_{i}^{d}}}^{l}\left[b r_{i}+\left(1-\frac{b}{2}\right)\right] d r_{i}=\left(1+\frac{b}{2} \underline{r}\right)(1-\underline{r}) \\
& q_{i}^{d}=P\left(r_{i}>\underline{r_{i}^{d}} \mid x_{L}\right)=\int_{\underline{r_{i}^{d}}}^{1}\left[-b r_{i}+\left(1+\frac{b}{2}\right)\right] d r_{i}=\left(1-\frac{b}{2} \underline{r}\right)(1-\underline{r})
\end{aligned}
$$

From equations $(6 \mathrm{a}-\mathrm{b})$ we can see that $p_{i} \geq q_{i}$ since $r \in(0,1)$. Now that we have completed the framework for analyzing risky project evaluation in organizations, we state our results in the next section.

\section{Results}

In this paper, we assume that there is no information problem in the sense that the principal can observe the actions of the agents. In this case, the optimum for the principle is to bear all risk by herself, and pay all agents a constant salary $s$, independent of the outcomes of the project. The principle gives each of the agents a cut-off point $r_{i}$ to decide whether to accept or reject the risky project. If after working, the agent i gets a signal $r_{i}<r_{i}$, he rejects the risky project. On the other hand, if $r_{i}>r_{i}$, he accepts the risky project. The signal $r_{i}$ each agent gets is assumed to be conditionally independent.

If the principle wants to maximize her expected profits, she will prefer to choose different cut-off points for different organizations. It is reasonable to expect that the optimal evaluation rule may be stricter in $\mathrm{P}$ since it is enough for the project to be approved by one agent in $\mathrm{P}$, whereas both of the agents in $\mathrm{H}$ has to accept the project for it to be accepted by the organization. The results for $\mathrm{H}$ and $\mathrm{P}$ are obtained by using equations (1)-(4) and are given equations ( $7 \mathrm{a}-\mathrm{c})$ and Figures $3 \mathrm{a}-\mathrm{c}$ and Figures $4 \mathrm{a}-\mathrm{b}$ below. Here, f stands for first-best full-information case:

$$
\begin{aligned}
& r_{f}^{H}(\alpha)=\frac{\left[-6+b(-1+\alpha)-6 \alpha+\sqrt{b^{2}\left(-1+\alpha^{2}\right)+4 b\left(-1+\alpha^{2}\right)+4\left(1+34 \alpha+\alpha^{2}\right)}\right]}{[4 b(-1+\alpha)]} \text { if } \alpha \neq 1 \\
& =\frac{1}{3} \text { if } \alpha=1 \\
& r_{f}^{P}(\alpha)=\frac{\left[-6+3 b(-1+\alpha)-6 \alpha+\sqrt{b^{2}\left(-1+\alpha^{2}\right)-4 b\left(-1+\alpha^{2}\right)+4\left(1+34 \alpha+\alpha^{2}\right)}\right]}{[4 b(-1+\alpha)]} \text { if } \alpha \neq 1 \\
& =\frac{2}{3} \text { if } \alpha=1 \\
& r^{*}(\alpha)=\frac{\left[-4+b(-1+\alpha)-4 \alpha+\sqrt{b^{2}\left(-1+\alpha^{2}\right)+64 b}\right]}{[2 b(-1+\alpha)]} \text { if } \alpha \neq 1 \\
& =\frac{1}{2} \text { if } \alpha=1
\end{aligned}
$$




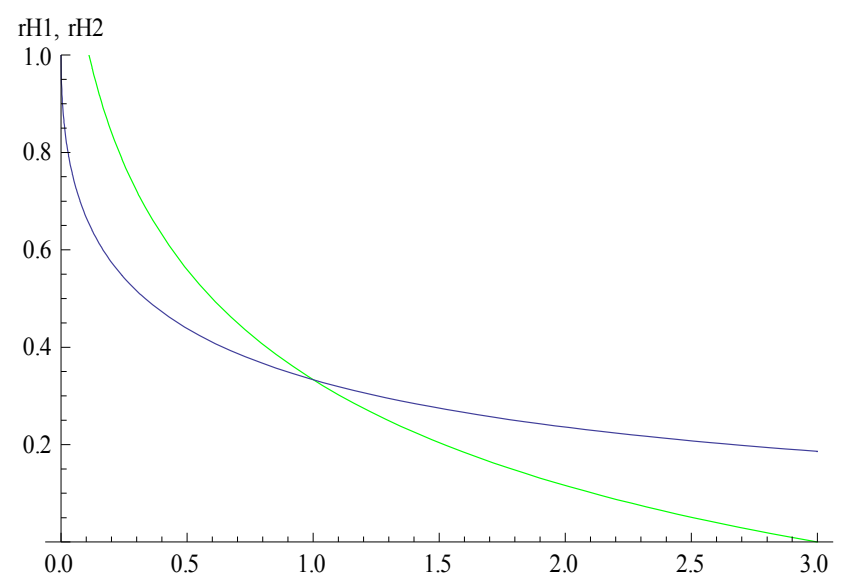

Figure 3a. The cut-off value $r_{f}^{H}$, for $b=1,2$. The line starting from 1 represents higher quality

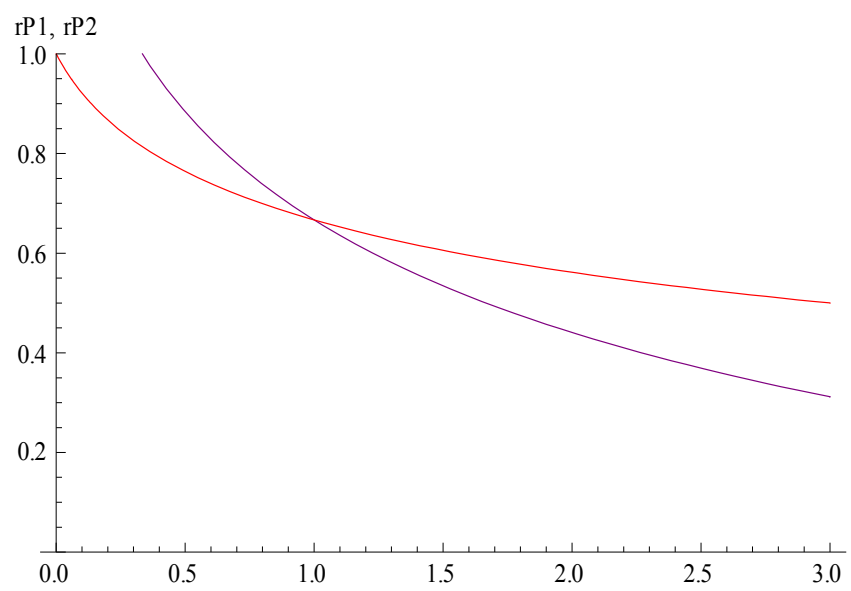

Figure $3 \mathrm{~b}$. The cut-off value $r_{f}^{P}$, for $b=1,2$. The line starting from 1 represents higher quality

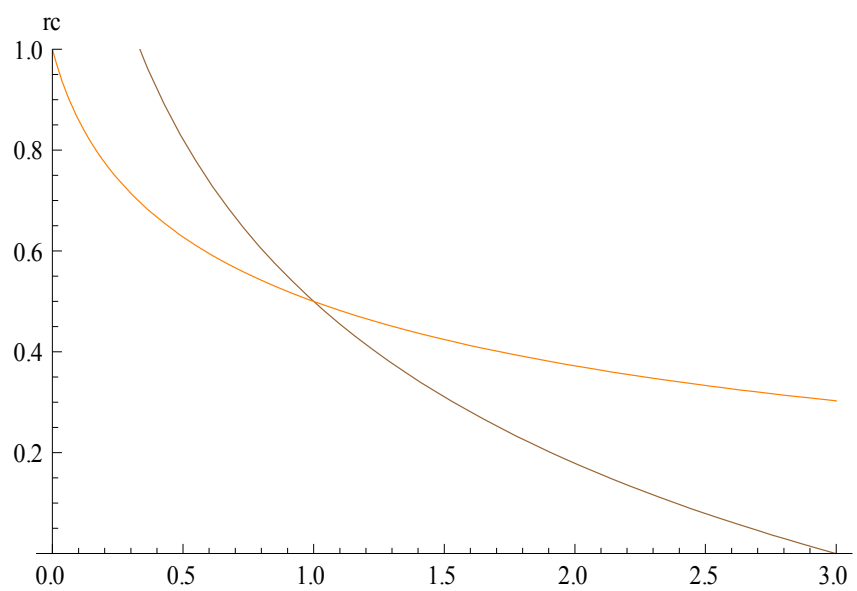

Figure $3 \mathrm{c}$. The cut-off value $r^{*}$, for $b=1,2$. The line starting from 1 represents higher quality

Figures 3a-b indicate that, first, the value of the cut-off point decreases with increasing quality of the project, both in $\mathrm{H}$ and $\mathrm{P}$. Second, they indicate that the deterioration in the information signal indicated by a lower value of $b$ causes a higher (lower) value of the cut-off point for $\alpha<1(\alpha>1)$, respectively, both in $\mathrm{H}$ and $\mathrm{P}$.

On the other hand, equation (7c) represents the case of the critical cut-off point when the performance of $\mathrm{H}$ and $\mathrm{P}$ are the same. Figure $3 \mathrm{c}$ gives the cut-off point for different values of the quality of the information signal. First, we have to note that above the line $\mathrm{H}$ is preferred to $\mathrm{P}$, and vice versa below the line. Second, as the information 
quality deteriorates, the critical cut-off point increases for below-average quality projects, and decreases for above-average quality projects. This means that $\mathrm{P}$ is preferred more often for below-average and $\mathrm{H}$ more often for above-average projects with deteriorating information signal quality.

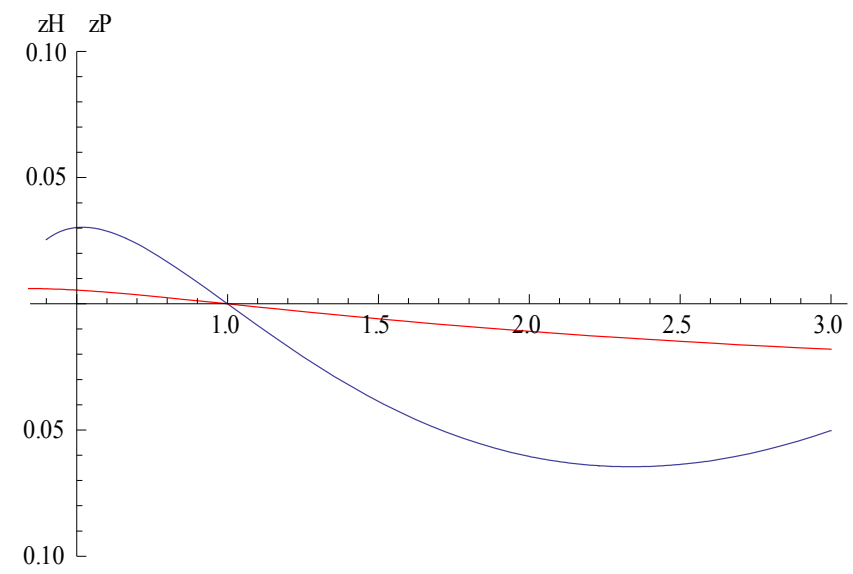

Figure 4a. The difference between the objective functions of $\mathrm{H}$ and $\mathrm{P}, Z^{H}-Z^{P}$, for $b=1$, 2, the lower line representing $b=1$

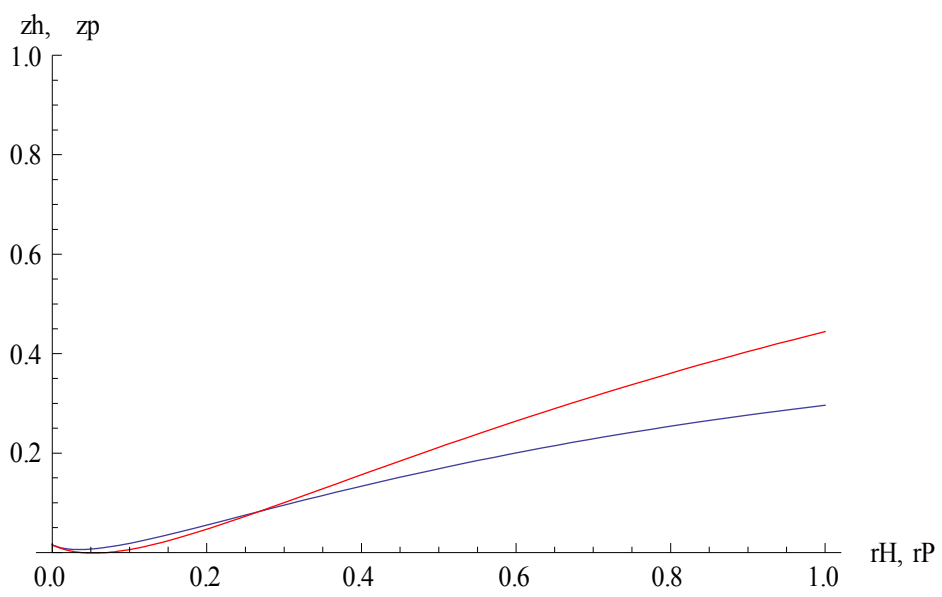

Figure $4 \mathrm{~b}$. The difference between the objective functions of $d=H, P, Z^{d 1}-Z^{d 2}$ for $b=1$, 2, where increasing information signal quality reveals better performance. The higher line represents $P$

On the other hand, Figures 4a-b indicate that, first of all $\mathrm{H}$ is preferred to $\mathrm{P}$ for $\alpha<1(\alpha>1)$ that is when the project quality is "below average" ("above average"), respectively. Furthermore, a decline in the information signal quality as represented by a lower value of $b$, magnifies the difference between the performance of the two organizations represented by expected outcomes in the relevant regions. Finally, the deteriorating information signal quality as represented by a lower value of $b$, decreases the expected outcome in both organizations.

As a further point, we should state the fact that $\mathrm{H}$ and $\mathrm{P}$ represent two ends of a continuum of possible organization types. If we let $\gamma \in[0,1]$ represent the "level of coordination of agents' decisions", a value $\gamma=$ 0 would represent "total coordination-total dependence" of decisions as in $\mathrm{H}$; and $\gamma=1$ would represent "no coordination-independence" of decisions as in P. Any other value of $\gamma$ would represent "partial coordination of agents' decisions". The following equation gives a possible coordination mechanism between the agents' decisions in a linear weighted average framework, where $\gamma_{i} \in[0,1]$ for $i=1,2,3$ and $\gamma_{1}+\gamma_{2}+\gamma_{3}=1$ :

$$
r^{\text {coord. }}(\alpha)=\gamma_{1} r_{f}^{H}(\alpha)+\gamma_{2} r^{*}(\alpha)+\gamma_{3} r_{f}^{P}(\alpha)
$$

As the last comment on this section, we might analyze the case of "good information signal-high agent ability", represented by $b=2$, estimated form equations (7a-c) and given in Figure 5. 


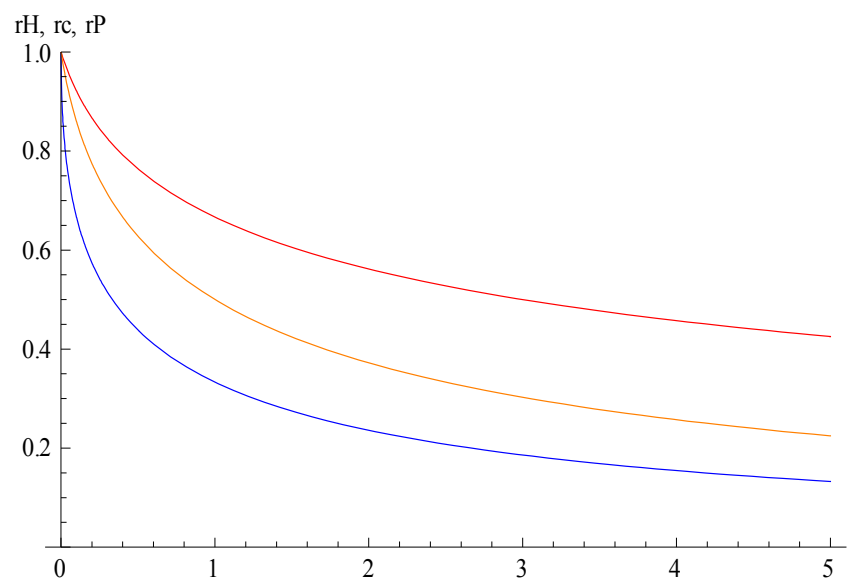

Figure 5. The cut-off value $r_{f}^{H}, r^{*}, r_{f}^{P}$ for $b=2$, in an increasing manner, respectively

Figure 5 may be analyzed to establish the relationship between different cut-off points, such that first of all, the cut-off points in $\mathrm{H}$ is lower than that in $\mathrm{P}$, for all values of the quality of the risky project $\alpha$. This is to be expected, since the second agent in $\mathrm{H}$ will also examine the project in case it is accepted, which is not the case in $\mathrm{P}$. Furthermore, there is a critical cut-off point value where the performance of $\mathrm{H}$ and $\mathrm{P}$ are equal. In the region above the line $\mathrm{H}$ is preferred to $\mathrm{P}$ and vice versa. Note that this critical cut-off point is not necessarily in the midpoint of $r_{f}^{H}, r_{f}^{P}$ except for the case when $\alpha=1$.

\section{Analysis}

In this section, we want to find answers to the questions we set out at the beginning of the paper based on the model and results of the previous section.

\subsection{Ability of the Agents}

Different abilities of agents are modeled with the information signal quality. As the information signal quality decreases, the cut-off point increases in below-average projects and vice versa in both $\mathrm{H}$ and $\mathrm{P}$. Furthermore, decreasing information signal quality decreases the expected outcome in both organization types. The result that $\mathrm{H}$ is preferred to $\mathrm{P}$ for below-average projects (and vice versa) still continues to hold, and with an increasing difference in performance, as the information signal quality deteriorates. The results for different ability agents would give similar results to the ones described above. On the other hand, the ordering of different ability agents in either organization would be irrelevant since project evaluation is simultaneous.

\subsection{Endogenity of the Organization}

The condition of whether the organization type is given as a "choice" variable-endogenous, or an "adaptation" variable-exogenous, determines the conduct of the principle. If the project quality is below-average, she prefers $\mathrm{H}$ to $\mathrm{P}$ (and vice versa). The cut-off points chosen would be a function of the project quality and would be chosen to maximize expected returns. On the other hand, if the organization type is forced from outside exogenously, then it is also possible for the principle to adopt to the situation by immunizing herself to organization type (choosing the critical cut-off point as a function of the project quality). She can also choose any point in between the maximizing and immunizing cut-off points to the degree of the force imposed or probability of such a force from outside for the choice of organization type.

\subsection{Sensitivity to Risk}

The risky and risk-free projects may be treated as equal alternatives only to the extent that risk-ignorant behavior prevails. In case the principle's risk sensitivity is greater than zero, and there is a price to risk as given by the Sharp Ratio (SR) (as analyzed in our recent paper Seber, 2014), the project quality will detoriorate and the organization choice will be different. Since deteriorating project quality favors $\mathrm{H}$, it will be preferred more often than $\mathrm{P}$.

\subsection{Change in Project Quality}

Different environments are analyzed about project quality, whether it is fixed-(below-above average) or variable, which requires adoptation. If the project quality is known to be a certain type, or it is possible to choose the organization type separately for each separate project with its associated quality, then the expected-outcome 
maximizing organization type will be chosen. On the other hand, if the organization type is to be chosen beforehand to deal with several variable quality projects, then the principle can choose the immunizing cut-off point value herself, being indifferent to appropriate organization type.

\subsection{Communication between the Agents}

It is possible to improve information signal quality with prositive communication between the agents and vice versa. Since improving information signal quality improves expected outcomes in both organizations, communication will add value. On the other hand, if the agents are affected from each others choice or communication creates confusion for any reason, it may also reduce expected outcome in both organization types by deteriorating information signal quality. However, the choice of $\mathrm{H}$ or $\mathrm{P}$ would not change for below-average or above-average projects, respectively, with communication. It would only change the choice of the cut-off value.

\subsection{Coordination between the Agents}

Coordination may be needed to keep the organization together, if it is not externally formed and has to be kept together internally (that is there is no principle to set up the organization). In this case, since the agents are affected from each others choices they may have to inform each other of their analysis and choice. They may decide on a weighting rule among themselves to determine project choice criteria together. It is also possible for the projects to be agent-specific, but the decision to affect the other agent as well, which would again necessitate coordination.

\section{Conclusion}

The detailed study of conditional probability density functions and thereby the comparison of organizations in terms of the cut-off point and the acceptance probabilities of the risky project is possible with the specific linear information signal function framework given in the paper. Furthermore, it is possible to model different ability of agents with the chosen information signal function. The mean and standard deviation of the linear function are in congruence with increasing or decreasing quality of the signal. The choice of $\mathrm{H}$ or $\mathrm{P}$ doesn't change with deteriorating information signal quality $(\mathrm{H}$ chosen when the project quality is below-average, and $\mathrm{P}$ when it is above-average). The magnitude of the performance difference between the two organizations magnifies, however, with deteriorating information signal quality. There may also be two different approaches to the cut-off point evaluation criteria choice in each organization: Making the project evaluation immune to organizational type; or maximizing expected returns from implementation of the risky project. Immunity does not ensure maximum expected returns, but may be preferred if the organization choice is not endogenous, but exogenous. Furthermore, the model allows for a multidimensional analysis depending on: Sensitivity to risk since the risky and risk-free projects are not identical if the principle is not risk-ignorant; whether the quality of portfolio of projects to be chosen are fixed or variable; whether there is a possibility of welfare enhancing communication between the agents; and whether coordination between the agents to keep the organization together is necessary or not.

\section{References}

Austen-Smith, D., \& Banks, J. S. (1996). Information aggregation, rationality and the Condorcet jury theorem. American Political Science Review, 90, 34-45. http://dx.doi.org/10.2307/2082796

Ben-Yashar, R., \& Nitzan, S. (1997). The optimal decision rule for fixed size comittees in dichotomous choice situations: The general result. International Economic Review, 38(1), 175-187. http://dx.doi.org/10.2307/2527413

Ben-Yashar, R., \& Nitzan, S. (1998). Qualiy and structure in organizational decision making. Journal of Economic Behaviorvor and Organization, 36, 521-534. http://dx.doi.org/10.1016/S0167-2681(98)00109-7

Ben-Yashar, R., \& Nitzan, S. (2001). The robustness of optimal organizational architectures: A note on hierarchies and polyarchies. Social Choice and Welfare, 18, 155-163. http://dx.doi.org/10.1007/s003550000065

Ben-Yashar, R., \& Paroush, J. (2001). Optimal decision rules for fixed size committees in polychotomous choice situations. Social Choice and Welfare, 18, 737-746. http://dx.doi.org/10.1007/s003550000080

Berg, S., \& Paroush, J. (1998). Collective decision making in hierarchies. Mathematical Social Sciences, 35 , 233-244. http://dx.doi.org/10.1016/S0165-4896(97)00047-4

Dekel, E., \& Piccione, M. (2000). Sequential voting procedures in symmetric binary elections. Journal of Political Economy, 108, 34-55. http://dx.doi.org/10.1086/262110 
Feddersen, T., \& Pesedorfer, W. (1998). Convicting the innocent: The inferiority of unanimous jury verdicts under strategic voting. American Political Science Review, 92, 23-35. http://dx.doi.org/10.2307/2585926

Gradstein, M., Nitzan, S., \& Paroush, J. (1990). Collective decision making and the limits on the organization size. Public Choice, 66, 279-291. http://dx.doi.org/10.1007/BF00125779

Klevorick, A. K., \& Rothschild, M. (1979). A model of jury decision process. Journal of Legal Studies, 8, 141164. http://dx.doi.org/10.1086/467604

Klevorick, A. K., Rothschild, M., \& Winship, C. (1984). Information processing and jury decisionmaking. Journal of Public Economics, 23, 245-278. http://dx.doi.org/10.1016/0047-2727(84)90031-8

Koh, W. T. H. (1992a). Variable evaluation costs and the design of fallible hierarchies and polyarchies. Economic Letters, 38, 313-318. http://dx.doi.org/10.1016/0165-1765(92)90077-C

Koh, W. T. H. (1992b). Human fallibility and sequential decision making: hierarchy versus polyarchy. Journal of Economic Behavior and Organization, 18, 317-345. http://dx.doi.org/10.1016/0167-2681(92)90014-3

Koh, W. T. H. (1993). Firs-mover advantage and organizational structure. Economic Letters, 43, 47-52. http://dx.doi.org/10.1016/0165-1765(93)90133-W

Koh, W. T. H. (1994a). Making decisions in committees: A human fallibility approach. Journal of Economic Behavior and Organization, 23, 195-214. http://dx.doi.org/10.1016/0167-2681(94)90067-1

Koh, W. T. H. (1994b). Fallibility and sequential decision making. Journal of Institutional Theoretical Ecconomics, 150(2), 362-374.

Koh, W. T. H. (2005). Optimal sequential decision architectures and the robustness of hierarchies and polyarchies. Social Choice and Welfare, 24, 397-411. http://dx.doi.org/10.1007/s00355-003-0304-0

Li, H., Rosen, S., \& Suen, W. (2001). Conflicts and common interests in committees. American Economic Review, 21, 1478-1497. http://dx.doi.org/10.1257/aer.91.5.1478

Lambert, R. A. (1986). Executive effort and selection of risky projects. Rand Journal of Economics, 17(1), 6778. http://dx.doi.org/10.2307/2555629

Nitzan, S., \& Paroush, J. (1980). Investment in human capital and social self protection. International Economic Review, 21, 547-557. http://dx.doi.org/10.2307/2526351

Nitzan, S., \& Paroush, J. (1982). Optimal decision rules in uncertain dichotomous choice situations. International Economic Review, 23, 289-297. http://dx.doi.org/10.2307/2526438

Nitzan, S., \& Paroush, J. (1984). The significance of independent decisions in uncertain dichotomous choice situations. Theory Decision, 17(1), 47-60. http://dx.doi.org/10.1007/BF00140055

Nitzan, S., \& Paroush, J. (1985). Collective decision making: An economic outlook. London: Cambridge University Press.

Pete, A., Pattipati, K. R., \& Kleinman, D. L. (1993). Optimal team and individual decision rules in uncertain dichotomous situations. Public Choice, 75, 205-230. http://dx.doi.org/10.1007/BF01119183

Sah, R. (1990). An explicit closed form formula for profit maximizing k-out-of-n sysytems subject to two kind of failures. Microel Reliability, 30, 1123-1130. http://dx.doi.org/10.1016/0026-2714(90)90291-T

Sah, R. (1991). Fallibility in human organizations and political systems. Journal of Economic Perspectives, 5, 67-88. http://dx.doi.org/10.1257/jep.5.2.67

Sah, R. K., \& Stiglitz, J. E. (1985). The theory of economic systems: Human fallibility and economic organization. American Economic Review Papers and Proceedings, 75, 292-297.

Sah, R. K., \& Stiglitz, J. E. (1986). The architecture of economic systems: hierarchies and polyarchies. American Economic Review, 76, 716-727.

Sah, R. K., \& Stiglitz, J. E. (1988). Committees, hierarchies and polyarchies, Economic Journal, 98, 451-470. http://dx.doi.org/10.2307/2233377

Seber, A. (2014). Alternative measures for modeling risk and expected utility theory. International Journal of Economics and Finance, 6(9). http://dx.doi.org/10.5539/ijef.v6n9p151

Seber, A., \& Wu, H. M. (2000). Risky project evaluation and organizational design: hierarchies and polyarchies. Working paper. 
Stiglitz, J. (2002). Information and the change in the paradigm in economics. American Economic Review, 92(3), 460-501. http://dx.doi.org/10.1257/00028280260136363

Visser, B. (2000). Organizational communication structure and performance. Journal of Economic Behavior and Organization, 42, 231-252. http://dx.doi.org/10.1016/S0167-2681(00)00087-1

\section{Copyrights}

Copyright for this article is retained by the author(s), with first publication rights granted to the journal.

This is an open-access article distributed under the terms and conditions of the Creative Commons Attribution license (http://creativecommons.org/licenses/by/3.0/). 